\title{
Effect of Solanum melongena peel extract in the treatment of arsenical keratosis
}

\author{
Quazi Sahely Sarah and Mir Misbahuddin
}

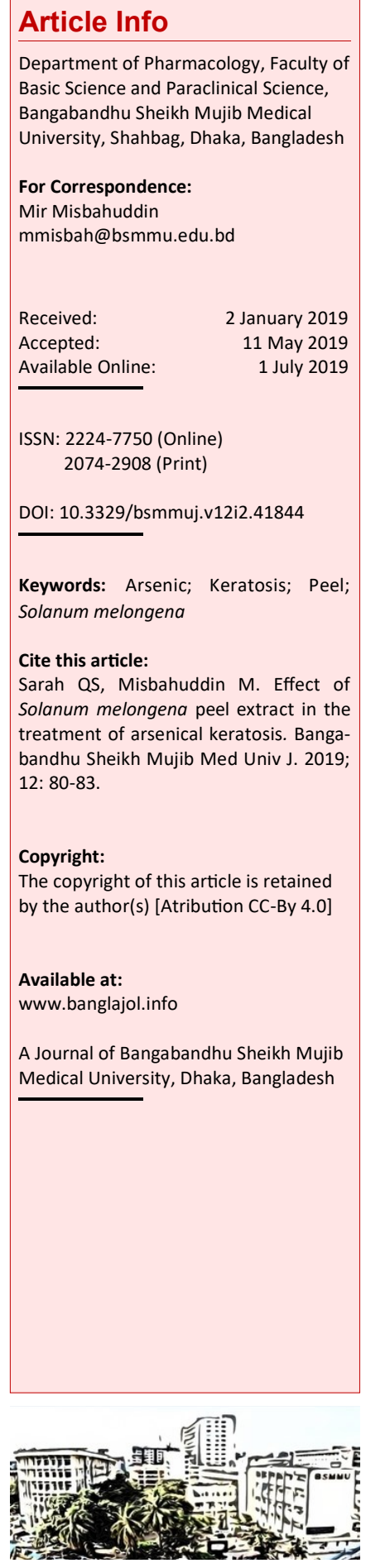

\begin{abstract}
This study was conducted to examine the effect of the ointment containing Solanum melongena peel extract in the treatment of arsenical keratosis. In total, 23 patients were enrolled on the basis of inclusion and exclusion criteria. The ointment was given to each patient and advised him/her to apply to the site of lesion twice daily for 12 weeks without any gap. The size of the lesion and its photograph were collected before and at the end of the study. The mean $( \pm$ SD) diameter of the lesion was $3.9 \pm 2.1 \mathrm{~cm}$ which reduced to $1.8 \pm 1.3 \mathrm{~cm}$ (reduction $54 \%$ ). The results were statistically significant. In conclusion, S. melongena peel extract is found to be effective in the treatment of arsenical keratosis.
\end{abstract}

\section{Introduction}

Chronic ingestion of high concentration $(>50$ $\mu \mathrm{g} / \mathrm{L})$ of arsenic in drinking water for more than six months may lead to arsenicosis. 1 The common clinical symptoms are the skin manifestations characterized by melanosis, leucomelanosis and keratosis. 2 Other manifestations are diabetes, hypertension, bronchitis and malignancy of some organs especially skin, lungs and urinary bladder. 3,4

Among the non-malignant skin manifestations, keratosis creates social problem particularly in the case of unmarried girl or recently married woman. $\underline{5}$ The disease may cause problem in family life and sometimes may cause divorce. It appears in both palms and soles. One peculiarity is that keratosis does not appear in one palm or one sole.

There is, still now, no effective treatment of keratosis. Researchers are suggesting oral administration of some anti-oxidant vitamins, minerals, spices, and vegetables.1 However, the efficacy of these treatments needs prolong time and recurrence occur after stoppage of medicines. Some medicines such as salicylic acid, 6 propylene glycolz are advised topically. The high concentration of salicylic acid is needed which may cause burning sensation during its use.

A recent study from the same laboratory shows that topical application of an ointment containing S. melongena peel extract is effective in the treatment of arsenic-induced Bowen's disease. Therefore, this study was conducted to see whether the ointment of $S$. melongena peel extract was effective in the management of arsenical keratosis.

\section{Materials and Methods}

The study was conducted in two arsenic affected endemic areas [Bhanga Upazilla of Faridpur District (about $150 \mathrm{~km}$ from Dhaka) and Sirajdikhan Upazilla of Munshiganj District (about 25 $\mathrm{km}$ from Dhaka)] from September 2016 to January 2018.

The study was conducted on 23 patients (male 10, female 13) of moderate to severe arsenical keratosis (both palms and soles). The inclusion criteria were a) age (18-65 years); b) both sex; c) consumption of drinking water $>50 \mu \mathrm{g} / \mathrm{L}$ of arsenic for more than six months; d) moderate to severe keratosis; and e) voluntarily agreed to participate in this study. The exclusion criteria were a) pregnancy, b) lactating mother and c) the patient who received any treatment of arsenicosis within the last three months. One of the patients' house was used as a temporary arsenic clinic. Each patient was requested to attend that clinic. The clinical examination of patient and distribution of ointment containing S. melongena peel extract were done at 2 weeks interval.

Detailed history, clinical examination, and photographs of the lesions were collected. The drinking water used by the patient and his/her nails were collected to measure the amount of arsenic. The advice was given to each patient how to apply the ointment at the site of the lesion.

The size of the lesions was measured both just before and after completion of the treatment.

One polyethylene container (100 mL size) containing 1 drop of nitric acid was supplied to 
each patient in order to collect the drinking water sample used by himself/herself. All the collected samples were then transported to the Department and stored until analysis.

The hand and toe nails of each patient were collected $(>200 \mathrm{mg}$ ) and properly stored in a supplied plastic bag. Finally transported to the laboratory and stored until analysis.

The amount of arsenic in water and nails was measured by modified silver diethyldithiocarbamate (SDDC) method.9

The S. melongena fruit was identified by Mr. Khandokar Kamrul Islam (Scientific Officer), Bangladesh National Herbarium, Dhaka, Bangladesh.

The size of each S. melongena was $8 \times 2$ inches. The skin color was purple. In total, $12 \mathrm{~kg}$ were collected from the local vegetable market. These were initially washed and then peeled off the skin from the pulp using a peeler. The peels were divided into small pieces. The remaining parts of the fruit were discarded. The pieces of peels were finally air-dried at room temperature.

The pieces of peel (about $500 \mathrm{~g}$ ) were immersed into a wood bark color bottle (size: 2.5 liters) containing 2 liters of a mixture of ethanol: chloroform: acetic acid (65: 32: 3). The mixture was kept at room temperature for 72 hours. Then the solvent was free from the solid parts using Whatman filter paper. The filtrate was then concentrated at temperature $\left(40-50^{\circ} \mathrm{C}\right)$ and reduced pressure using a rotary evaporator until a semi-solid substance (color: dark brownish) was obtained. The peel extract was stored in a wood bark color container and kept in a refrigerator until use. The procedure was repeated several times. About $2 \mathrm{~g}$ extract was obtained from $4 \mathrm{~kg}$ of peels (yield $0.05 \%$ ).

\section{Brine shrimp lethality study}

The eggs of brine shrimp (Artemia salina) were collected from a local market. Fifteen gram of eggs were poured into a glass container (square shaped; capacity $=6 \mathrm{~L}$ ) containing artificial seawater (about $4 \mathrm{~L}$ ) for hatching for 48 hours with continuous aeration and artificial light (60-watt bulb). 10 Within this period, all the active nauplii were free from the eggshells.

An analytical balance was used to weigh the peel extract of $1 \mathrm{mg}$. Sterile test tubes (size: 5 inches) were taken and labeled. The extract was dissolved in water $(1 \mathrm{~mL})$ to prepare the stock solution. The serial dilutions of stock solution were done $(100,10$, 1.0, $0.1 \mu \mathrm{g} / \mathrm{mL})$. One milliliter of the prepared solution was taken into 5 test tubes containing 10 live nauplii/ $1 \mathrm{~mL}$ of artificial sea-water containing different concentrations of the extract.

Test tubes were then incubated at room temperature. The active movement of nauplii was observed after 2 and 24 hours.

$\%$ Death $=\frac{\text { No. of dead nauplii }}{\text { No. of dead nauplii }+ \text { No. of live nauplii }} \times 100$

The ointment $(100 \mathrm{~g})$ contained $30 \mathrm{mg}$ of peel extract. All the ingredients were measured by either a measuring cylinder or an electronic balance. A bowl $(100 \mathrm{~mL})$ containing water was heated up to boiling by a burner. A beaker containing olive oil $(90 \mathrm{~mL})$ was placed into the boiling water.11 When the temperature was increased to $90^{\circ} \mathrm{C}$, then bee wax $(10 \mathrm{~g})$ was added to it. When melting of the bee wax was completed, the burner was put off. The beaker was placed to cool down at room temperature. Benzoic acid $(10 \mathrm{mg})$ and peel extract $(30 \mathrm{mg})$ were then added and contentiously beat until it became thick. It was transferred into plastic screw cap container ( $20 \mathrm{~g}$ each). Each container was stored in a refrigerator until distributed to the patient.

The ointment was distributed to each patient and was instructed to apply the ointment to the affected area of the skin by clean fingertip twice daily (morning and bedtime). A separate printed sheet was given to check the adherence by the patient by giving a tick mark just after applying of the ointment.

The keratotic lesion was monitored. Any improvement was documented and check the adherence. The communication to each patient by the researcher was done regularly using cell phone.

\section{Statistical analysis}

The statistical analysis was done using Student's ttest to compare the lesion size of keratotic lesion before and after treatment. Data were mean \pm SD.

\section{Results}

The mean $( \pm \mathrm{SD})$ age of patients was $45.6 \pm 12.1$ years (Table I). The mean amount of arsenic in the tube-well water that was consumed by the patients was $742.1 \pm 214.8 \mu \mathrm{g} / \mathrm{L}$. The mean amount of arsenic in the nail was $21.9 \pm 7.7 \mu \mathrm{g} / \mathrm{g}$. The duration of exposure to arsenic-contaminated water was 19.0 \pm 9.1 years. The duration of the appearance of the keratotic nodules was $13.4 \pm 5.5$ years.

One patient was drop out due to loss to follow-up.

Size of the lesions: The size (mean \pm SD) of the nodules during the enrollment was $3.9 \pm 2.1 \mathrm{~cm}$ which was reduced to $1.8 \pm 1.3 \mathrm{~cm}$ after 12 weeks of the medication (54\% reduction) (Figure 1). This change was statistically significant $(p=0.00001)$. The elevation of the keratotic nodules was reduced.

Perception of the patients: The perception score of the arsenicosis patients before the medication was 


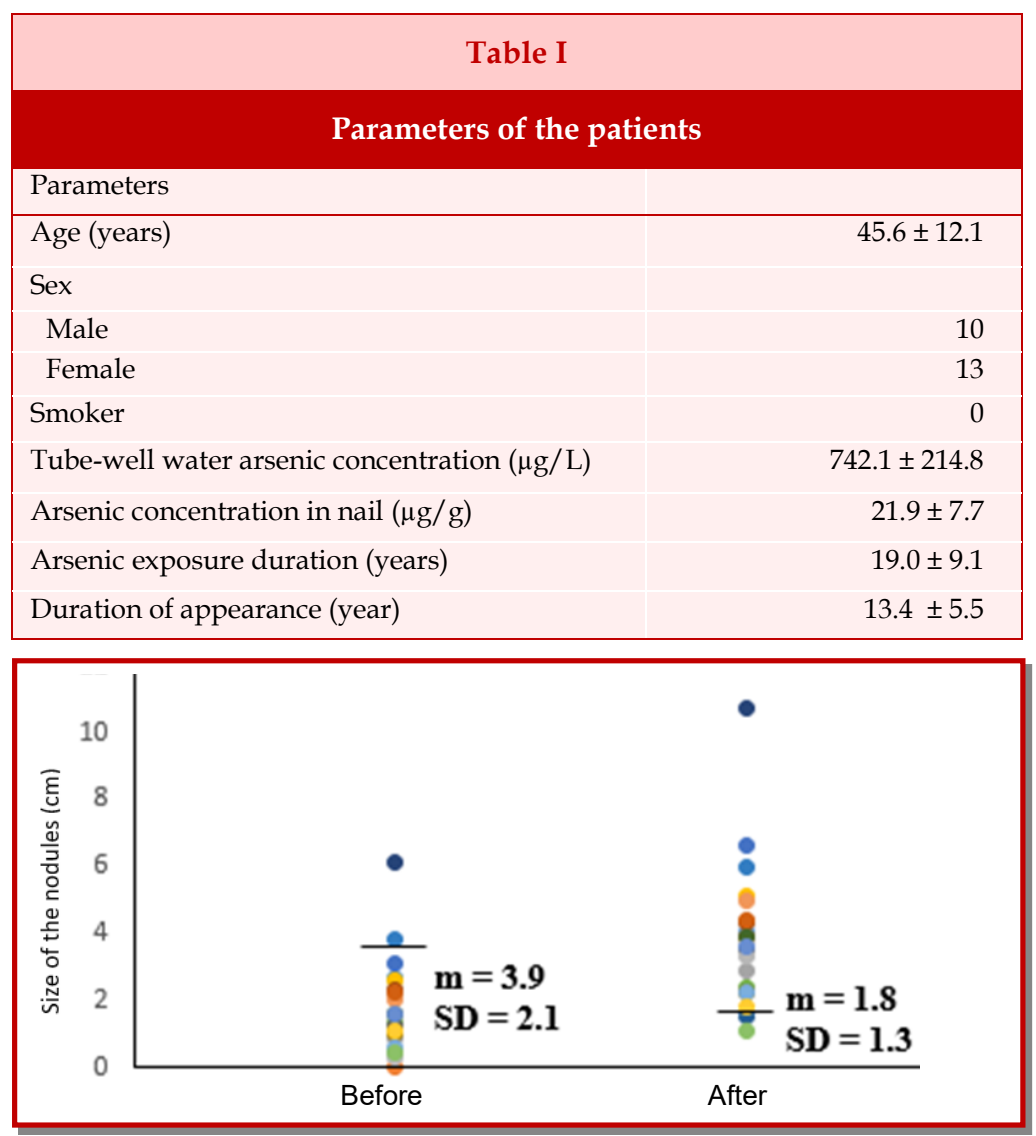

Figure 1: Size of the keratotic lesion both before and after topical application of the $S$. melongena peel extract

$1.7 \pm 2.9$ on a scoring scale (0-6). After 12 weeks of completion of medication, the mean improvement score was $13.1 \pm 16.2$.

Adverse effects: There was no adverse effect during and after medication.

Brine shrimp toxicity assay: $10 \mu \mathrm{L} / \mathrm{mL}$ concentration of the extract showed lethal effect to the brine shrimp.

\section{Discussion}

This study showed a significant improvement in the clinical symptoms of arsenical keratosis by the ointment containing peel extract of S. melongena.

S. melongena is a widely used vegetable. The peel of this vegetable is violet in color. The peel mainly contains nasunin, chlorogenic acid, solasodine glycosides and solamargine. 12 The nasunin and chlorogenic acid are anti-oxidants. $\underline{13}$ The solasodine glycosides are cytotoxic in nature. Topical treatment of malignant and premalignant skin lesion by very low concentrations of standard mixture of solasodine glycosides improves the clinical condition. $\underline{14} \mathrm{~A}$ study explained the mode of action of solamargine as a potent cytotoxic activity against tumor cells by initiate a death process named oncosis. $\underline{15}$ Nasunin showed biological abilities to prevent the production of free radicals, induces apoptosis, inhibits cell proliferation and angiogenesis.

The mechanism by which peel extracts cures the arsenical keratosis is not clear. It may be due to antioxidant as well as cytotoxic effects of its components. The topically applied salicylic acid reduces the symptoms of keratosis by its soothing effect.

\section{Conclusion}

S. melongena peel extract is found to be effective in the treatment of arsenical keratosis.

\section{Conflict of interest}

The authors have declared no conflict of interest.

\section{Acknowledgement}

We acknowledge the patients of two arsenic affected endemic areas for their co-operation during the study.

\section{Ethical Issue}

The protocol was approved by the Institutional Review Board of the Bangabandhu Sheikh Mujib Medical University.

\section{References}

1. Misbahuddin M. Arsenicosis: A global issue. New York, Science Publishing Group, 2015, pp 1-204.

2. Caussy D. A field guide for detection, management and surveillance of arsenicosis cases. New Delhi, WHO Regional Office for South-East Asia, 2005.

3. Rahman M, Tondel M, Chowdhury IA, Axelson O Diabetes mellitus associated with arsenic exposure in Bangladesh. Am J Epidemiol. 1998; 148: 198-203.

4. Rahman M, Tondel M, Ahmad SA, Chowdhury IA, Faruquee MH, Axelson O. Hypertension and arsenic exposure in Bangladesh. Hypertension 1999; 33: 74-78.

5. Syed EH, Poudel KC, Sakisaka K, Yasuoka J, Ahsan $\mathrm{H}$, Jimba M. Quality of life and mental health status of arsenic-affected patients in a Bangladeshi population. J Health Popul Nutr. 2012; 30: 262-69.

6. Islam AZM, Misbahuddin M, Sikder S, Biswas AK, Islam Z, Hadiuzzaman, Khandaker S, Mahmud I, Ahmed SA. Randomized controlled trial to evaluate the effectiveness of topical use of salicylic acid for treatment of keratosis in arsenicosis. Applied 
Research on Arsenic in Bangladesh, Dhaka. World Health organization (Bangladesh), Director General of Health services, Government of Bangladesh, 2007, pp 93-102.

7. Dina AN, Misbahuddin M. Randomized doubleblind trial to evaluate the effectiveness of topical administration of propylene glycol in arsenical palmer keratosis. Bangladesh J Pharmacol. 2010; 5: 98-102.

8. Sarah Q, Misbahuddin M. Effect of Solanum melongena peel extract in the treatment of arsenicinduced Bowen's disease. Bangladesh J Pharmacol. 2018; 13: 309-15.

9. Bhuiyan HA, Tshering K, Misbahuddin M. Estimation of arsenic in nail using silver diethyldithiocarbamate method. Bangladesh J Pharmacol. 2015; 10: 513-17.

10. Sarah Q, Anny F, Misbahuddin M. Brine shrimp lethality assay. Bangladesh J Pharmacol. 2017; 12: 186-89.
11. Block LH. Ointments. In: Remington: The science and practice of pharmacy. Gennaro AR (ed). 20th ed. Vol 1. 2000, pp 845-46.

12. Niño-Medina G, Urías-Orona V, Muy-Rangel MD, Heredia JB. Structure and content of phenolics in eggplant (Solanum melongena): A review. South Afr J Bot. 2017; 111: 161-69.

13. Gallo M, Naviglio D, Ferrara L. Nasunin, an antioxidant anthocyanin from eggplant peels, as natural dye to avoid food allergies and intolerances. Eur Sci J. 2014; 10.

14. Cham BE, Daunture B, Evans RA. Topical treatment of malignant and premalignant skin lesion by very low concentrations of standard mixture (BEC) of solasodine glycosides. Cancer Lett. 1991; 59: 18392.

15. Sun L, Zoha Y, Yuan H, Li X, Cheng A, Lou H. Solamargine, a steroidal alkaloid glycoside, induces oncosis in human K562 leukemia and squamous cell carcinoma KB cells. Cancer Chemother Pharmacol. 2011; 67: 813-21. 